\title{
Magnetization as an Effective Tool for Kinetics Evaluation in Mechanochemical Synthesis of Chalcopyrite $\mathrm{CuFeS}_{2}$
}

\author{
P. BAlÁZ̆ $\check{Z}^{a, *}$, M. BAlÁZ̆ ${ }^{a}$, E. Dutkováa ${ }^{a}$, M. Hegedus ${ }^{b}$, \\ M. RAJŇÁK ${ }^{c, d}$, K. KNížEK ${ }^{e}$, J. HejtmáneK ${ }^{e}$, J. NAVRÁtiL ${ }^{f}$, \\ M. ACHIMOVIČOVÁ ${ }^{a}$ AND J. BRIANČIN ${ }^{a}$ \\ ${ }^{a}$ Institute of Geotechnics, SAS, Watsonova 45, 04001 Košice, Slovakia \\ ${ }^{b}$ Varmind s.r.o., Nové Sady 988/2, 60200 Brno, Czech Republic \\ ${ }^{c}$ Institute of Experimental Physics, SAS, Watsonova 47, 04001 Košice, Slovakia \\ ${ }^{d}$ Faculty of Electrical Engineering and Informatics, Technical University of Košice, Letná 9, 04200 Košice, Slovakia \\ ${ }^{e}$ Institute of Physics of the Czech Academy of Sciences, Cukrovarnická 10/112, 162 00, Praha 6, Czech Republic \\ ${ }^{f}$ University of Pardubice, Faculty of Chemical Technology, Studentská 573, 53210 Pardubice, Czech Republic
}

Copper, iron, and sulphur in elemental form were applied for mechanochemical synthesis of chalcopyrite $\mathrm{CuFeS}_{2}$. Products of synthesis were characterized by XRD method and evaluated by Rietveld analysis. A mixture of cubic (JCPDS 75-6866) and tetragonal (JCPDS 37-0471) phases of chalcopyrite with almost identical diffractograms were identified. Both phases are nanocrystalline with sizes $13 \mathrm{~nm}$ and $7 \mathrm{~nm}$ for laboratory and industrial milling, respectively. For determination of iron consumption during the synthesis, method of magnetometry has been applied. Based on magnetization data reflecting time dependent incorporation of elemental iron into chalcopyrite nanostructure, the kinetics of the synthesis was evaluated. From kinetic data the rate constant of reaction $k$, as well as the conversion degree $R$ were determined. High conversion degree of mechanochemical synthesis performed in a laboratory mill $(R=100 \%)$, as well as in an industrial mill $(R=96 \%)$ offer the possibility to scale-up the process of synthesis in preparation of this perspective magnetic semiconductor. The method of magnetometry was proved to be an effective tool for following the processes of synthesis where iron particles are incorporated.

DOI: 10.12693/APhysPolA.137.647

PACS/topics: 81.05.Bx, 81.07.Wx, 81.20.Wk

\section{Introduction}

Chalcopyrite $\mathrm{CuFeS}_{2}$ is a semiconductor with unusual magnetic and electrical properties. Depending on applied stress (e.g. high pressure, high-energy milling, etc.) the naturally occuring ordered tetragonal phase $\left(\alpha-\mathrm{CuFeS}_{2}\right)$ can show the structural and magnetic transitions [1]. These changes can influence the fundamental physical properties like optical band gap, electrical conductivity, and thermoelectric performance $[2-5]$.

The aim of this paper is to evaluate the kinetics of chalcopyrite $\mathrm{CuFeS}_{2}$ synthesis via mechanochemical route. Magnetometry is applied to follow the kinetics of this solid state synthesis. The possibility to scale-up the synthesis in an industrial mill [6] is also tested.

\section{Experimental}

\subsection{Mechanochemical synthesis}

Mechanochemical synthesis of chalcopyrite $\mathrm{CuFeS}_{2}$ was performed according to the reaction

$$
\mathrm{Cu}+\mathrm{Fe}+2 \mathrm{~S} \rightarrow \mathrm{CuFeS}_{2} .
$$

\footnotetext{
*corresponding author; e-mail: balaz@saske.sk
}

Two types of mills were used for the synthesis:

- laboratory planetary ball mill Pulverisette 6 (Fritsch, Germany) filled with mixture $1.73 \mathrm{~g}$ of $\mathrm{Cu}$ (99.7\%, Merck, Germany), $1.52 \mathrm{~g}$ of Fe (extra pure, Merck, Germany) and $1.75 \mathrm{~g}$ of S (99\%, Ites, Slovakia) used as reaction precursors. The milling was carried out in an argon atmosphere at revolutions $550 \mathrm{rpm}$ using a tungsten carbide milling chamber ( $250 \mathrm{~mL}$ in volume) filled with $360 \mathrm{~g}$ of 50 balls from tungsten carbide (10 $\mathrm{mm}$ in diameter). Milling time was $15-120$ min.

- industrial eccentric vibratory ball mill ESM 656-0.5 ks (Siebtechnik, Germany) filled with $34.6 \mathrm{~g}$ of $\mathrm{Cu}$ (99.7\%, Merck, Germany), $30.4 \mathrm{~g}$ of Fe (extra pure, Merck, Germany) and $35 \mathrm{~g}$ of S (99\%, CG Chemikalien, Germany) used as reaction precursors. The milling was carried out in an argon atmosphere using a tungsten carbide milling chamber (5L in volume) filled with $30 \mathrm{~kg}$ of balls from tungsten carbide ( $35 \mathrm{~mm}$ in diameter). Amplitude of the vibrations was $20 \mathrm{~mm}$, rotational speed of the eccenter was $960 \mathrm{~min}^{-1}$. Milling time was $60-720 \mathrm{~min}$.

\subsection{Characterization methods}

The XRD data were collected using a D8 Advance diffractometer (Bruker, Germany) with a $\theta-\theta$ goniometer, 
working with $\mathrm{CuK}_{\alpha}$ radiation. The data were collected over the angular range $2 \theta=20^{\circ}-90^{\circ}$ with scanning steps of 0.03 and the measurement step time interval of $6 \mathrm{~s}$. For the data processing, the commercial Bruker tools have been used. For the phase identification, the Diffracplus Eva and the ICDD PDF2 database and for Rietveld analysis, the Diffracplus Topas software have been applied.

The magnetic measurements were performed by a vibrating sample magnetometer installed on a cryogen-free system equipped with $18 \mathrm{~T}$ superconducting magnet from Cryogenic Ltd, England.

A nitrogen-adsorption apparatus NOVA 1200e Surface Area \& Pore Size Analyzer (Quantachrome Instruments, Great Britain) was employed to record sorption data at the temperature of liquid nitrogen. The specific surface area values $\left(S_{\mathrm{BET}}\right)$ were calculated using the BrunauerEmmett-Teller (BET) equation.

Scanning electron microscopy (SEM) images of the samples were recorded using MIRA3 FE-SEM microscope (TESCAN, Czech Republic) equipped with EDX detector (Oxford Instrument, United Kingdom).

Degree of conversion $R$ for (1) was calculated using

$$
R=\left(1-\frac{M}{M_{0}}\right) \times 100(\%),
$$

where $M$ is the magnetization of milled sample at magnetic field $5.5 \mathrm{~T}\left(\mathrm{~A} \mathrm{~m} \mathrm{~m}^{2} / \mathrm{kg}\right)$ and $M_{0}$ is the magnetization of non-milled sample at magnetic field $5.5 \mathrm{~T}\left(\mathrm{~A} \mathrm{~m}^{2} / \mathrm{kg}\right)$. Empirical equation, applied for solid state reactions in [7], of the form

$$
R=k_{1}+k_{2} t+k_{3} t^{2}
$$

was applied also for processing of kinetic data, where $t$ is the milling time $(\min )$ and $k_{1}, k_{2}$ and $k_{3}$ are the reaction rate constants $\left(\min ^{-1}\right)$. The initial rate constant $k_{i}\left(\min ^{-1}\right)$ was deduced from the initial slope as determined by fitting the experimental data to (3).

\section{Results and Discussion}

A series of experiments was performed in a laboratory and an industrial mill. Chalcopyrite $\mathrm{CuFeS}_{2}$ is formed in both cases as a final product (1). XRD diffractograms of end products of the syntheses are shown in Fig. 1. It is not possible to unambiguously assign crystal structure neither to the sample prepared in a laboratory or an industrial mill. This is due to large FWHM values of Bragg reflections. $\mathrm{CuFeS}_{2}$ phase can crystallize both in cubic (JCPDS card no. 75-6866) or tetragonal (JCPDS card no. 37-0471) crystal system with closely related cell parameters leading to almost identical diffractograms. Generally, tetragonal form is more abundant in nature. A change from tetragonal to cubic form may be induced by increased temperature, pressure or milling [8]. Thus, in the case of mechanosynthesized samples, a mixture of both forms may be present. To prove this, additional inspection of the system must be performed utilizing Raman spectroscopy. Besides chalcopyrite, the binary sulfides like $\mathrm{CuS}, \mathrm{FeS}_{2}$, and others as reaction intermediates

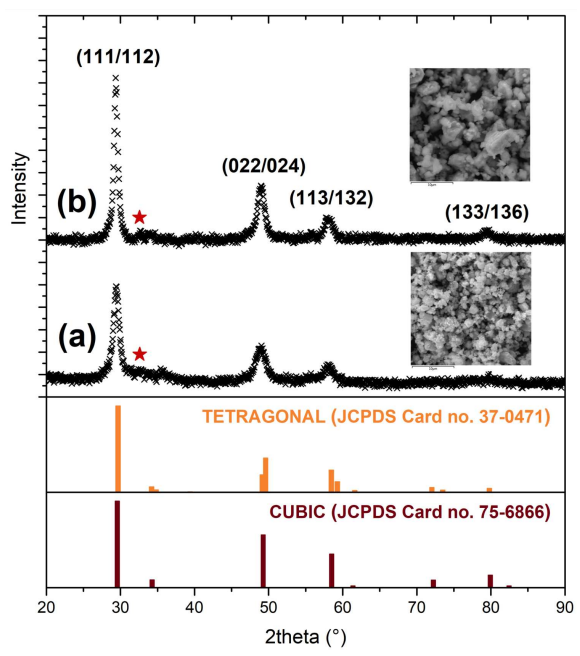

Fig. 1. Powder diffraction patterns of mechanochemically synthesized $\mathrm{CuFeS}_{2}$ with corresponding SEM insets: (a) industrial milling for $720 \mathrm{~min}$, (b) laboratory milling for $60 \mathrm{~min}$. Miller indexes of corresponding crystallographic planes of tetragonal/cubic $\mathrm{CuFeS}_{2}$. Asterisk identifies the possible impurities of binary phases.

can be present in low amounts (see asterisk in Fig. 1), which is in accord with data in $[9,10]$. This may suggest longer reaction times needed or subsequent thermal treatment for completion of the mechanochemical synthesis. At this stage, it can be concluded that nanocrystalline chalcopyrite was successfully synthesized on both types of mills. The crystallite size $13 \mathrm{~nm}$ and $7 \mathrm{~nm}$ for laboratory and industrial milling was determined.

In order to evaluate the kinetics of mechanochemical synthesis, the magnetization data were measured for all milled samples. This approach is based on measurement of ferromagnetic iron consumption during the synthesis of antiferromagnetic chalcopyrite. This concept of kinetics evaluation has been used in previous papers where iron was applied as a reducing agent in mechanochemical reductions [11, 12]. Measurements of magnetization $M$ have been performed in our case with both sets of samples (see Fig. 2). In accord with Fig. 1, the more severe treatment in a laboratory mill gives the lower values of $M$ in comparison with the results in an industrial mill. Consequently, the more rapid progress can be expected in the case of laboratory milling.

The data of saturated magnetization $M$ at magnetic field $B=5.5 \mathrm{~T}$ and temperature of $298 \mathrm{~K}$ shown in Fig. 2 were processed according to (2), and plotted together with values of specific surface area in dependence on milling time $t$ in Fig. 3. Stagnation of $S_{\mathrm{BET}}$ values at high milling times is a sign of intensive progress of reaction (1).

Overall, the total conversion to chalcopyrite ( $R=96-100 \%$ ) was obtained upon the treatment in both. However, the rate of reaction (1) as manifested by initial rate constants is 7.2 times higher, and the reaction time necessary for total conversion $R$ is shorter 

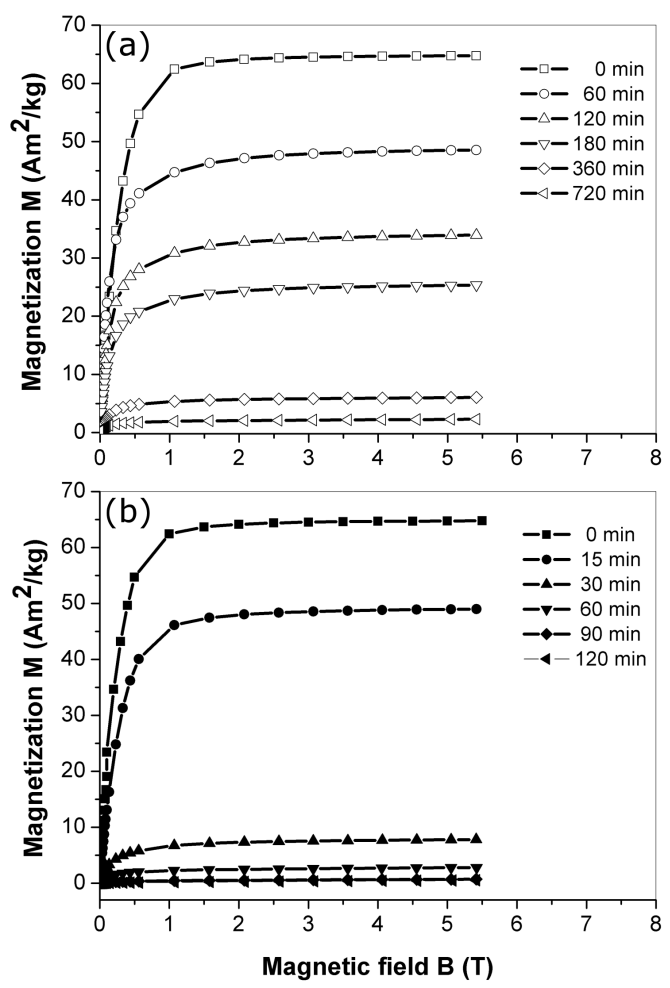

Fig. 2. Magnetization $M$ vs. magnetic field $B$ for mechanochemical synthesis of $\mathrm{CuFeS}_{2}$ (a) industrial milling, (b) laboratory milling (milling time in Table legend).

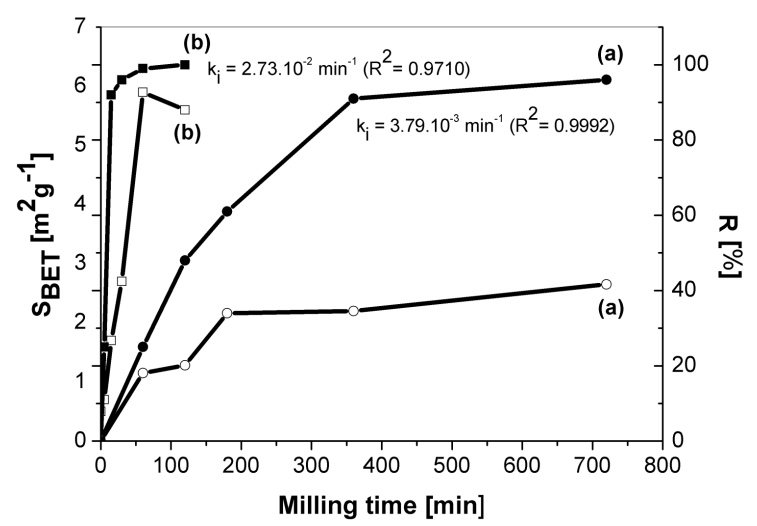

Fig. 3. Conversion degree $R$ and specific surface area $S_{\mathrm{BET}}$ vs. milling time $t$ for mechanochemical synthesis of $\mathrm{CuFeS}_{2}$ (a) industrial milling (circle), (b) laboratory milling (square). Full points - dependence of conversion degree $R$ on milling time $t$. Empty points - dependence of specific surface area $S_{\mathrm{BET}}$ on milling time $t$.

by milling at laboratory conditions. The milling in an industrial mill requires the optimization study which is beyond the scope of this paper. Moreover, contamination from milling balls composed from tungsten carbide can play role in special applications. For example, Co content in industrial milling was estimated $2518 / 2447 \mathrm{mg} / \mathrm{kg}$ in comparison with value $116.4 / 118.5 \mathrm{mg} / \mathrm{kg}$ determined for laboratory milling.

\section{Conclusions}

Chalcopyrite $\mathrm{CuFeS}_{2}$ was synthesized from elemental precursors by high-energy milling in $60 \mathrm{~min}$ and $720 \mathrm{~min}$ using lab-scale and semi-industrial scale mill, respectively. Its crystalline structure was confirmed from XRD data by Rietveld analysis. Product of mechanochemical syntheses consists of nanocrystalline particles. There size was determined $13 \mathrm{~nm}$ and $7 \mathrm{~nm}$ for laboratory and industrial milling, respectively. For determination of iron consumption during the solid state reaction magnetometry was applied. Based on magnetization data reflecting time dependent installation of elemental iron into chalcopyrite nanostructure the kinetics of the reaction was evaluated. From the kinetics data the initial rate constants of reaction $k$, as well as conversion degree $R$ were determined. The high conversion degree of mechanochemical synthesis performed in a laboratory mill $(R=100 \%)$ and in an industrial mill $(R=96 \%)$ offer the possibility to scale-up the synthesis process in production of this perspective magnetic semiconductor.

\section{Acknowledgments}

This work was promoted by the Slovak Research and Development Agency under the contract No. APVV18-0357. The support through the Slovak Grant Agency VEGA (projects $2 / 0044 / 18,2 / 0065 / 18$ ) is acknowledged. The support from the Czech Science Foundation (project $18-12761 \mathrm{~S})$ is appreciated.

\section{References}

[1] C. Boekema, A.M. Krupski, M. Varasteh, K. Parvin, F. van Til, F. van der Woude, G.A. Sawatzky, J. Magn. Magn. Mater. 272, 559 (2004).

[2] D.X. Liang, R.S. Ma, S.H. Jiao, G.S. Pang, S.H. Feng, Nanoscale 4, 6265 (2012).

[3] R. Ang, A.U. Khan, N. Tsujii, K. Takai, R. Nakamura, T. Mori, Angew. Chem. Int. Edit. 54, 12909 (2015).

[4] B. Li, B. Huang, M.Z. Zhong, Z.M. Wei, J.B. Li, RSC Adv. 5, 91103 (2015).

[5] T. Wen, Y.G. Wang, N.N. Li, Q. Zhang, Y.S. Zhao, W.E. Yang, Y.S. Zhao, H.K. Mao, J. Am. Chem. Soc. 141, 505 (2019).

[6] P. Balaz, M. Hegedus, M. Achimovicova, M. Balaz, M. Tesinsky, E. Dutkova, M. Kanuchova, J. Briancin, ACS Sustain. Chem. Eng. 6, 2132 (2018).

[7] J.E. Dutrizac, Metall. Trans. B Process Metall. 12, 371 (1981).

[8] P. Balaz, K. Tkacova, E.G. Avvakumov, J. Therm. Anal. 35, 1325 (1989).

[9] J.H. Li, Q. Tan, J.F. Li, J. Alloys Comp. 551, 143 (2013).

[10] E. Dutkova, Z. Bujnakova, J. Kovac, I. Skorvanek, M.J. Sayagues, A. Zorkovska, J. Kovac, P. Balaz, Adv. Powder Technol. 29, 1820 (2018).

[11] A. Calka, A. Mosbah, N. Stanford, P. Balaz, J. Alloys Comp. 467, 477 (2009).

[12] P. Balaz, E. Dutkova, I. Skorvanek, E. Gock, J. Kovac, A. Satka, J. Alloys Comp. 483, 484 (2009). 